\title{
Assessment of the Shrinkage and Ejection Forces of Reinforced Polypropylene based on Nanoclays and Short Glass Fibre
}

\author{
M. C. R. Garcia ${ }^{1, a}$, A. C. S. Netto ${ }^{1, b}$, A. J. Pontes ${ }^{2, c}$ \\ ${ }^{1}$ Instituto Federal de Educação, Ciência e Tecnologia Sul-Riograndense \\ Av. Copacabana, 100 - Campus de Sapucaia do Sul, RS - 93216-120, Brasil \\ ${ }^{2}$ Institute for Polymers and Composites, IPC/I3N, Department of Polymer Engineering, \\ University of Minho, Campus of Azurém - 4800-058 Guimarães, Portugal \\ amauro@sapucaia.ifsul.edu.br, basabino@ifsc.edu.br, cpontes@dep.uminho.pt
}

Keywords: shrinkage, ejection force, nanoclay, short glass fibre

\begin{abstract}
In this study the influence of nanoclay and glass fibre in the shrinkage and ejection forces in polypropylene matrix in tubular parts moulded by injection moulding were analysed. An instrumented mould was used to measure the part surface temperature and ejection forces in tubular parts. The materials used were a polypropylene homopolymer Domolen $1100 \mathrm{~L}$ nanoclay for polyolefin nanocomposites P-802 Nanomax in percentages of $2 \%, 6 \%$ and $10 \%$ and a polypropylene homopolymer with content of $10 \%$ of glass fibre Domolen P1-013-V10-N and 30\% of glass fibre Domolen P1-102-V30-N with $2 \%$ of nanoclay. The shrinkage and ejection forces were analysed. The results show that the incorporation of nanoclays decreases the shrinkage and ejection forces whereas glass fibre decreases the shrinkage and increase ejection forces due to the increase of the elastic modulus. The nanoclays decrease the ejection force when compared with glass fibre and pure PP. The effects of nanoclays are less pronounced than those of glass fibre.

The effect of the mould temperatures on the ejection forces in the mouldings produced with the mentioned materials were also analysed. The ejection force decreases with the increase of the temperature of the mould.
\end{abstract}

\section{Introduction}

Injection moulding of fibre filled thermoplastics is an easy way of mass producing complex composite products with stiffness properties superior to those of unreinforced polymer products [4, 9].

The field of nanotechnology is one of the most popular areas for current research and development in basically all technical disciplines. This obviously includes polymer science and technology and even in this field the investigators cover a broad range of topics [1]. Many researchers have been studying the effects of nanocomposites, especially nanoclays, in thermoplastics materials. János Móczó et. al [2,3] have studied that the characteristics of all heterogeneous polymer systems including composites containing either micro or nanofillers are determined by four factors: component properties, composition, structure and interfacial interactions. The most important filler characteristics are particle size, size distribution, specific surface area and particle shape, while the main matrix property is stiffness. Segregation, aggregation and the orientation of anisotropic particles determine structure. Interfacial interactions lead to formation of a stiff interphase considerably influencing properties. Interactions are changed by surface modification, which must be always specific and selected according to its goal. Under the effect of external load inhomogeneous stress distribution develops around heterogeneities, which initiate local micromechanical deformation processes determining the macroscopic properties of the composites.

The shrinkage of the moulding depends on many variables such as processing conditions, the polymer type and part geometry [5-8]. The moulding produced with short glass fibre has anisotropic shrinkage making difficult to predict the final dimensions and shape. 
The ejection force depends on the shrinkage of the polymer, the surface roughness of the mold and the coefficient of friction between the steel and the molded part, at the time of ejection [7].

This work aims to investigate the effects of nanoclays and glass fibre in the shrinkage and ejection forces in injection molding. It's very important because the force required to eject the part is a fundamental design variable that defines the design of the ejection system [7].

\section{Materials and processing}

The geometry of part is tubular (Fig. 1). An instrumented mould was used in this work. The mold is equipped with sensors for simultaneous monitoring of cavity pressure, temperature and ejection force.

The materials used were a homopolymer polypropylene DOMOLEN 1100L, nanoclay for polyolefin nanocomposites P-802 Nanomax in percentages of $2 \%, 6 \%$ and $10 \%$ and a polypropylene homopolymer with content of $10 \%$ and $30 \%$ of glass fibre reinforced Domolen P1013-V10-N and Domolen P1-102-V30-N, respectively, with $2 \%$ of nanoclay. The injection moulding machine used was a Ferromatik Milacron K85 with 85 tonnes of Clamp Force. The processing parameters were the same for all mouldings.

The shrinkage and ejection forces were analysed considering the mould temperatures of 30,50 and $75^{\circ} \mathrm{C}$. The measurement of the shrinkage in three positions along the flow path was done 48 hours after the processing of the moulded parts using a three-dimensional measuring machine (3DMM) from Tesa Company.

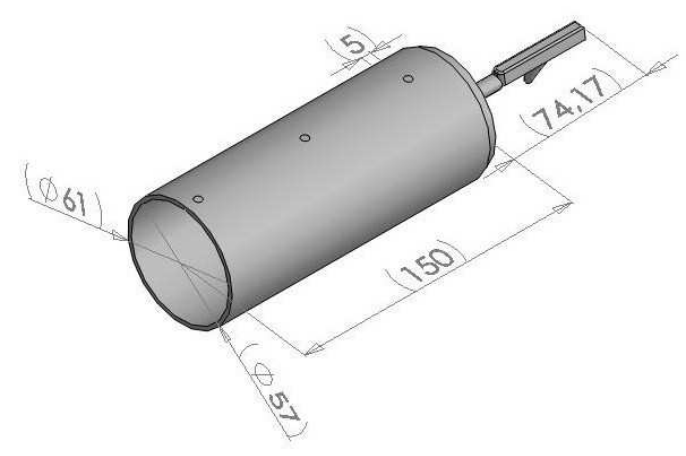

Fig. 1 - Tubular part

\section{Results and discussions}

It was observed that shrinkage decreases when the percentage of glass fibre increases, due to the constraint effect and lower expansion coefficient of the fibers [7]. The nanoclays also decrease the shrinkage of the material, but its effect is less pronounced than for glass fibre (Fig. 2). In relation to shrinkage measured along the flow path, the pure PP and PP with nanoclays shrink more far away from the gate than near to the gate. This behaviour is due to the fact that the gate is the last zone to freeze and, consequently, in this zone the material is more compacted due to the effect of the holding phase (pressure and time). In relation to the addition of nanoclay in polypropylene with glass fibre, no effect is observed for the material with $30 \%$ of glass fibre, but in the polypropylene with $10 \%$ glass fibre, the addition of $2 \%$ of nanoclays decreases the shrinkage. In this case it seems that the addition of the nanoclays on the material with $10 \%$ of glass fibre creates a synergetic effect on the reduction of the shrinkage. 


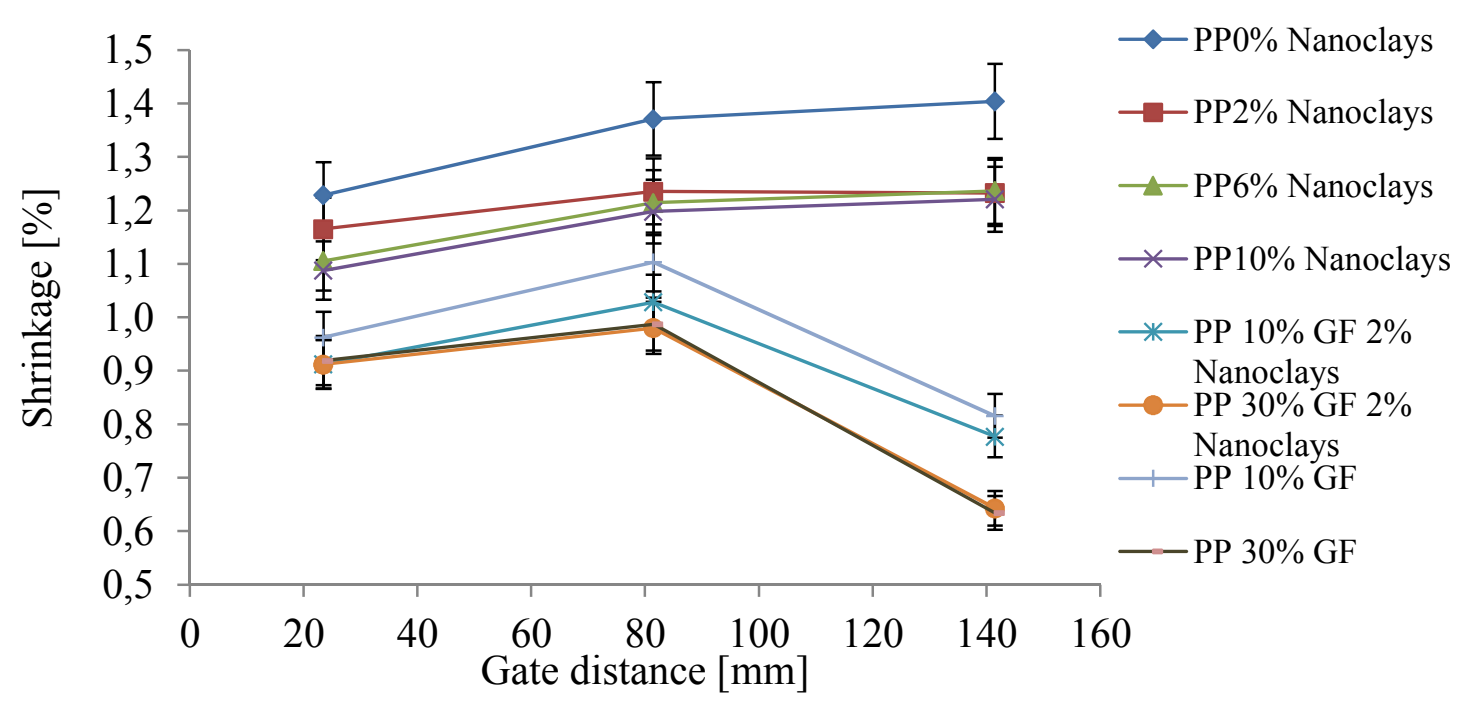

Fig. 2 - Shrinkage of external diameter for the mould temperature of $30^{\circ} \mathrm{C}$

When the mould temperature increases the shrinkage also increases. This behaviour is due to the fact that when the moulding is ejected at higher temperature the material has more time to shrink (Fig. 3). It is also possible to note that the reinforced materials present less shrinkage than pure PP. In this figure the effect of the addition of nanoclays into glass fibre polypropylene can also be observed. The presence of nanoclays decreases the shrinkage.

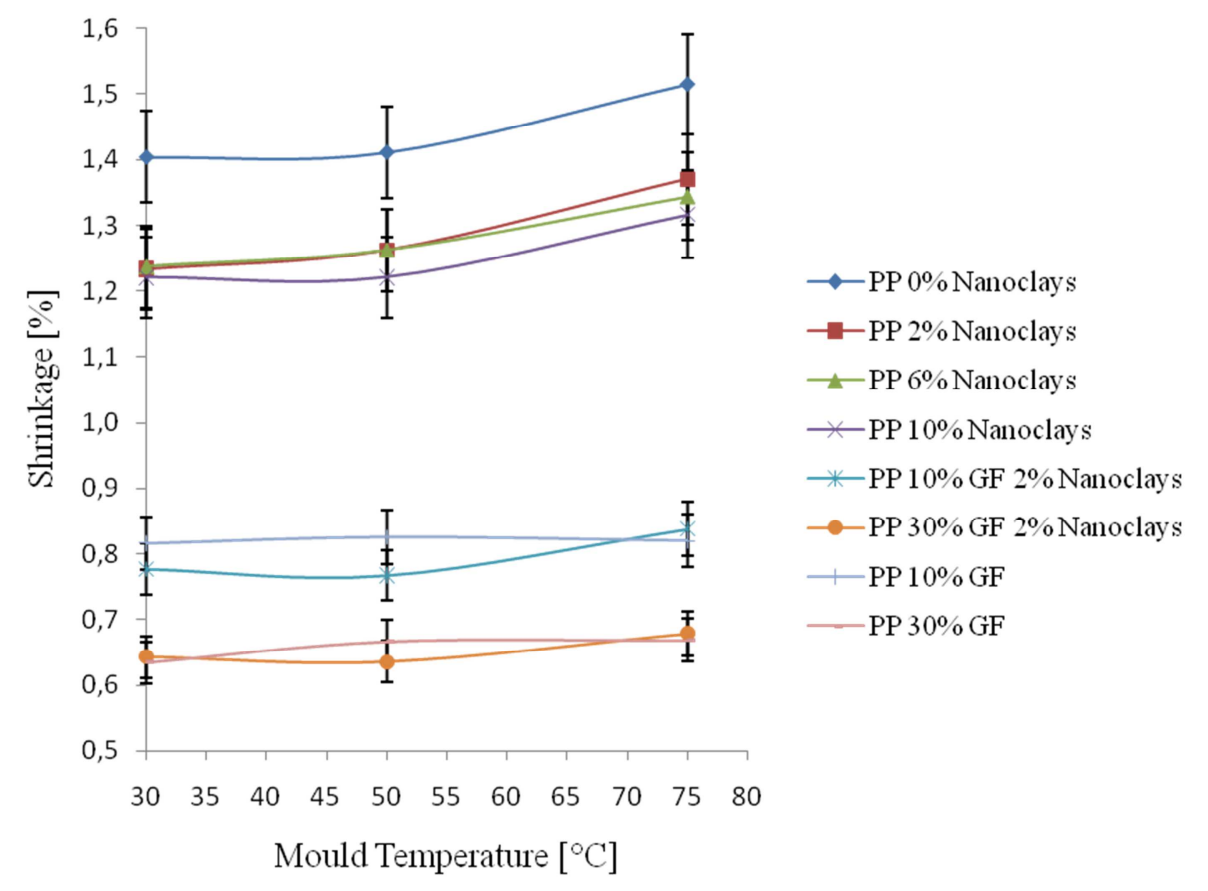

Fig. 3 - Shrinkage of external diameter for the mould temperatures.

In the Fig. 4 the results of the thickness shrinkage along the flow path are shown. The shrinkage is higher far away from the gate than near the gate as mentioned previously. For the position near the gate an expansion on the thickness direction (negative shrinkage) can also be observed. This behaviour is due to the fact that near the gate the material is over packed and when the mould opens the part expands. Afterwards, the part shrinks but not enough to compensate the expansion. The shrinkage increases far from the gate with increasing nanoclay content because nanoclay increases viscosity. Due to this fact, if the process parameters set remains unchanged, there will be less packing far from the gate. 

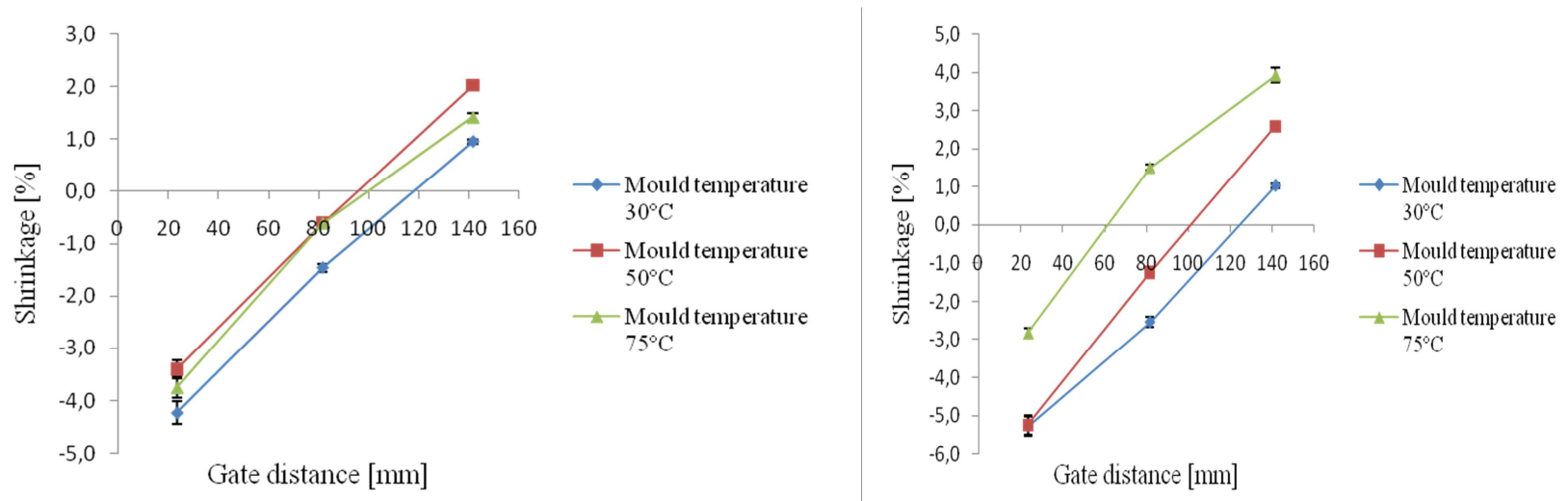

Fig. 4.1 - Thickness shrinkage PP 0\% nanoclay

Fig. 4.2 - Thickness shrinkage PP 2\% nanoclay

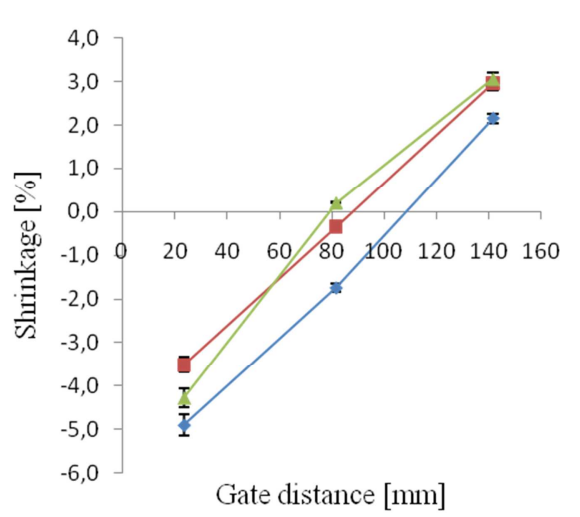

Fig. 4.3 - Thickness shrinkage $6 \%$ nanoclay

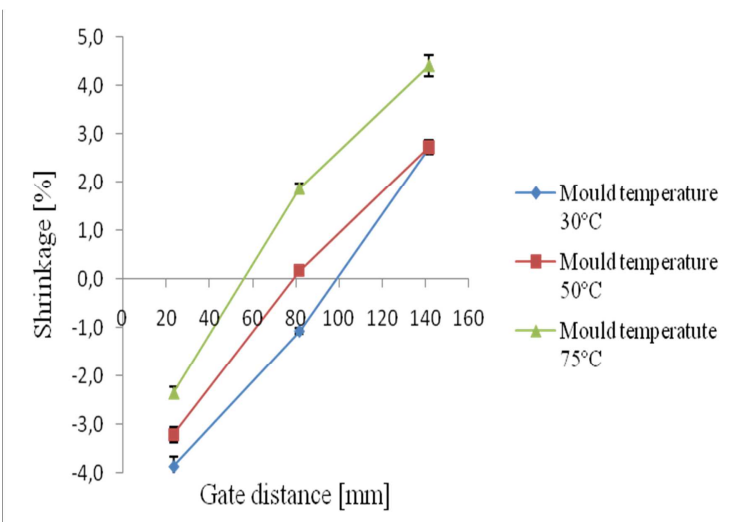

Fig. 4.4 - Thickness shrinkage $10 \%$ nanoclay

As could be observed in the figure 5 the ejection force decreases with the increase of mould temperature. The ejection force also increases with the increase of the glass fibres content, due to the higher elastic modulus, which hinders the ejection of the part from the mould.

The nanoclays decrease the ejection force when compared with glass fibres and pure PP (Fig. 5). When nanoclays are added to polypropylene with glass fibre the ejection forces decreases slightly when we compare the ejection forces of the mouldings produced with the material without nanoclays. This behaviour seems to indicate that the nanoclays reduce the shrinkage and the coefficient of friction and consequently reduce the ejection forces. 


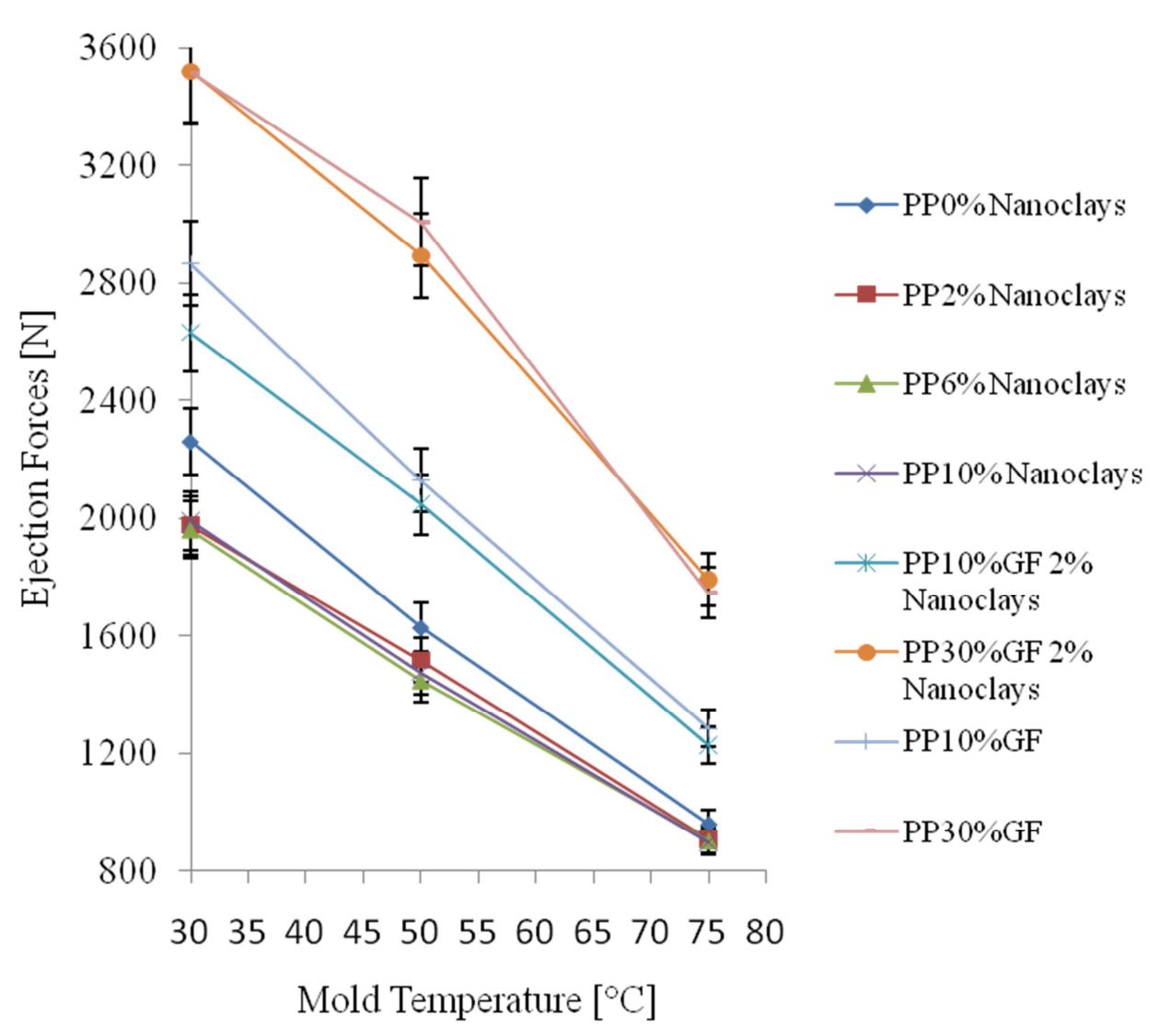

Figure 5 - Ejection forces in relation of the mould temperature

\section{Conclusions}

The incorporation of nanoclays decreases the shrinkage and ejection forces whereas glass fibre decreases the shrinkage and increase ejection forces due to the increase of the elastic modulus.

The effects of nanoclays are less pronounced than those of glass fibre in the shrinkage. In relation to the gate location, the pure PP shows higher shrinkage far away from the gate than near to the gate. This result is due to the fact that the gate is the last zone to freeze and, consequently, the holding pressure can be applied for a longer period. Increasing nanoclays content leads to increasing shrinkage far from the gate due to higher viscosity of nanoclay reinforced PP and thus lower local packing.

The glass fibre reinforced PP shows lower shrinkage far away from the gate than near to the gate. When higher temperature of the mould was observed the as-moulded shrinkage of the part also increases.

The ejection forces were also measured in the mouldings produced with the mentioned materials and the effect of the mould temperatures were analysed. The ejection force decreases with the increase of the temperature of the mould. This behaviour is explained by the fact that the elastic modulus and the shrinkage at ejection decrease with the increase of the average ejection temperature of the moulding. The ejection force also increases with the content of glass fibres in the material. This behaviour is explained by the fact that the increase of glass fibres content increases the elastic modulus.

In relation of inclusion of nanoclays into glass fibre polypropylene, the nanoclays tend to decrease the shrinkage and ejection forces. Probably the nanoclays act as lubricant in the polymer. 


\section{References}

[1] D. R. Paul, L. M. Robeson, R.A., Polymer nanotechnology: Nanocomposites, Polymer. 49 (2008) 3187-3304.

[2] J. Móczó, B. Pukánszky, Polymer micro and nanocomposites: Structure, interactions, properties, J. Industrial and Eng. Chemistry. 14 (2008) 535-563.

[3] Y. Termonia, Structure-property relationships in nanocomposites, Polymer. 48 (2007) 69486954.

[4] K. M. B. Jansen, D. J. Van Dijk, M. J. A. Freriksen, Shrinkage anisotropy in fibre reinforced injection molded products, Polymer Composites. 19 (1998) 325-334.

[5] G. Titomanlio, K. M.B. Jansen, In-mold shrinkage and stress prediction in injection molding, Polymer Eng. and Science. 36 (1996) 2041-2049.

[6] K. M. B. Jansen, D. J. Van Dijk, M. H. Husselman, Effect of processing conditions on shrinkage in injection molding, Polymer Eng. and Science. 38 (1998) 838-846.

[7] A. J. Pontes, A. M. Brito, A. S. Pouzada, Assessment of the ejection force in tubular injection moldings, J. Injection Molding Tech. 6 (2002) 343-352.

[8] K. M. B. Jansen, G. Titomanlio, Effect of pressure history on shrinkage and residual stresses injection molding with constrained shrinkage, Polymer Eng. and Science. 36 (1996) 20292040.

[9] M. R. Kamal, A. T. Mutel, L. A. Utracki, Elongational behavior of short glass fibre reinforced polypropylene melts, Polymer Composites. 5 (1984) 289-298. 